\title{
OUTRAS VOZES DA CANÇÃO POPULAR BRASILEIRA
}

\author{
Leandro Braz da Costa ${ }^{1}$ \\ Recebido em: 13/04/2020 \\ Aprovado em: 14/05/2020
}

\begin{abstract}
Resumo: Este ensaio apresenta algumas inflexões acerca da historiografia da música brasileira e a utilização da canção popular enquanto fonte utilizada no processo de ensino e aprendizagem em história, através de perspectivas sublinhadas por Jörn Rüsen, com enfoque nas manifestações socioculturais ligadas a produção musical das décadas de 1960, 70 e 80. Enquanto objetivo propõe chamar a atenção e discutir a inserção de canções populares produzida por músicos, intérpretes e compositores que estiveram desvinculados dos meios de comunicação de massa e da indústria fonográfica, apontando para a ampliação dos horizontes de pesquisa, ensino e aprendizagem em história, orientados por identidades e temporalidades que permeiam as pluralizadas culturas populares enquanto manifestações de conformismo e resistência.
\end{abstract}

Palavras-chave: Canção popular. Cultura popular. Historiografia. Ensino de História. História.

\section{OTRAS VOCES DE LA CANCIÓN POPULAR BRASILEÑA}

Resumen: Este ensayo presenta algunas inflexiones sobre la historiografía de la música brasileña y el uso de la canción popular como fuente utilizada en el proceso de enseñanza y aprendizaje en la historia, a través de perspectivas subrayadas por Jörn Rüsen, centrándose en las manifestaciones socioculturales vinculadas a la producción musical de los años sesenta. , 70 y 80. Como objetivo, propone llamar la atención y discutir la inserción de canciones populares producidas por músicos, intérpretes y compositores desconectados de los medios de comunicación y la industria fonográfica, con el objetivo de ampliar los horizontes de investigación, docencia y aprendizaje en la historia, guiado por identidades y temporalidades que permean las culturas populares pluralizadas como manifestaciones de conformidad y resistencia.

Palabras clave: Canción popular. Cultura popular. Historiografía. Enseñanza de la historia. Historia.

\section{OTHER VOICES OF THE BRAZILIAN POPULAR SONG}

Abstract: This essay presents some inflections about the historiography of Brazilian music and the use of popular song as a source used in the teaching and learning process in history, through

${ }^{1}$ Doutorando em História - Universidade Federal de Santa Maria (UFSM). Atua como Historiador na Associação dos Professores da Universidade Federal do Rio Grande - APROFURG, Universidade Federal do Rio Grande (FURG), Rio Grande-RS. E-mail: 1bcosta.furg@ gmail.com. ORCID: https://orcid.org/0000-0002-4632-7872. 
perspectives underlined by Jörn Rüsen, focusing on the socio-cultural manifestations linked to the musical production of the 1960s and 1970s. As an objective it aims to discuss the insertion of popular songs produced by musicians, interpreters and composers who have been disconnected from the mass media and the phonographic industry to the teaching of history, pointing to the widening of the horizons of research and learning, guided by identities and temporalities that permeate the pluralized popular cultures as manifestations of conformism and resistance.

Keywords: Popular song. Popular culture. Historiography. History teaching. History.

\section{Consolidação e desvios necessários}

Desconfianças quanto à disposição da música, especificamente acerca da canção popular brasileira (letra e música) enquanto fonte para a escrita da história, sobretudo, em virtude de uma considerável produção acadêmica com densidade teórica e metodológica, proveniente de artigos, livros, dissertações e teses, foram gradativamente sendo superadas no Brasil a partir da década de 1980. Estudiosos de diferentes áreas do conhecimento foram alguns dos precursores e contemporâneos na proposição de abordagens que contribuíram para o atual estágio de desenvolvimento das pesquisas no país.

Com a consolidação dessa seara, gradativamente a canção acabou sendo utilizada enquanto material didático fecundo que passou a orientar e contribuir no processo de ensino e aprendizagem histórica compreendida neste ensaio enquanto "a consciência humana relativa ao tempo, experimentando o tempo para ser significativa, adquirindo e desenvolvendo a competência para atribuir significado ao tempo.” (RÜSEN, 2010, p. 79), afinal, "a música é um artefato cultural que auxilia o ser humano a estabelecer relações com o meio. As formas e objetivos com que esse artefato foi e é utilizado ao longo de nossa trajetória histórica são variáveis em seus contextos históricos e sociais.” (SOARES, 2017, p. 83).

Enquanto reflexo do desenvolvimento das pesquisas realizadas no país o ensino de história acabou concentrando preferencialmente abordagens acerca da utilização de canções produzidas por compositores consagrados pelo público, com nível considerável de vendagem de discos e exposição midiática, atuantes no mercado cultural brasileiro e no exterior, com participação em grandes eventos e inseridos em movimentos musicais que marcaram época, como a Bossa Nova, a Jovem Guarda, o Tropicalismo ou a MPB.

Quando os enfoques compreendem, por exemplo, a história referente à Ditadura CivilMilitar brasileira, tanto no que diz respeito à produção historiográfica, quanto ao ensino de história através da utilização da produção musical das décadas de 1960 e 1970, pesquisadores 
e professores fazem uso, preferencialmente, das canções censuradas ou engajadas (NAPOLITANO, 2001, p. 117), bem como, da biografia dos grandes nomes da época a fim de desenvolverem finalidades especificas de ensino e pesquisa.

Nas décadas de 1960 e 1970 o Brasil vivenciou um período extremamente fértil de produção musical autoral, muito influenciado pelos inúmeros festivais de música que ocorreram em diversas regiões do país, mesmo "diante da vigilância, repressão e censuras enquanto reflexo do autoritarismo vigente aos setores de oposição ligados as manifestações artísticas" (NAPOLITANO, 2002, p. 11). Dentre esses acontecimentos musicais os mais destacados e pesquisados ainda são os Festivais de Música da Televisão, que tiveram sua gênese logo após o Golpe Civil-Militar de 1964, promovidos pelas emissoras Excelsior, Record, Rio e Globo entre os anos de 1965 a 1985 (MELLO, 2003). Estes afamados eventos ao mesmo tempo em que revelaram ao público brasileiro uma diversificada gama de intérpretes, compositores e instrumentistas acabaram aproveitados por artistas que obtiveram maior visibilidade e destaque, bem como, pelas gravadoras enquanto espaços ideais para aferir o alcance de público em relação a cada um dos artistas que subiam ao palco para apresentarem suas canções (TINHORÃO, 1981, p. 178). A historiografia da música brasileira, de forma preponderante, seguiu a mesma trilha.

Pari passu dos principais autores da historiografia da música brasileira em eventos dessa natureza houve predomínio da "música denominada jovem, transformando-se em clima do não conformismo, da crítica e agressividade às instituições" (NAPOLITANO, 2004, p. 107). A produção musical identificada com a sigla MPB (Música Popular Brasileira) passava por sua fase de consolidação, inserida a uma nova cultura de consumo, ao passo que, as imagens de "modernidade", "liberdade" e "justiça social” impregnaram as canções deste gênero durante a fase mais autoritária do Regime Militar, que incidia o controle a todos os setores da vida nacional, incluindo grande parte da atividade autoral dos artistas brasileiros (NAPOLITANO, 2002, p. 11), dentre as quais é possível citar, por exemplo, as canções Cálice (1973) de Chico Buarque e Gilberto Gil, bem como, Samba da Esperança (1973) de Vinicius de Moraes e Toquinho (SILVA, 1999, p. 57).

Ainda assim, em vista das escolhas e esforços que promovem constantes debates e avanços no campo do ensino e da pesquisa em história e música no Brasil, atualmente torna-se imprescindível chamar a atenção para o fato da existência de uma expressiva produção musical que foi manifestada no país por compositores, intérpretes e instrumentistas totalmente desvinculados do mercado fonográfico e que, por esse motivo, acabou não comercializada em formato de disco ou cassete, bem como, consequentemente não difundida pelos meios de 
comunicação da época (rádio e televisão), motivos pelos quais, acabou não aparecendo no conteúdo de livros didáticos de história, muito menos abordada em sala de aula pelos professores que, em grande medida, até mesmo, desconhecem sua existência.

\section{A canção e o popular na canção}

É, sobretudo com base no conteúdo textual (letra) das canções populares de compositores desconhecidos do grande público, as quais expunham suas concepções sociais em pluralizadas relações socioculturais e políticas, que atualmente podemos dispor de um panorama da atividade de muitos artistas da nossa música que estiveram desvinculados do mercado fonográfico e dos meios de comunicação de massa (rádio e televisão) ao longo dos anos 1960, 70 e 80, até mesmo porque são ínfimos e preciosos os registros sonoros de suas produções autorais, bem como, quaisquer materiais de divulgação de seus trabalhos, como por exemplo, entrevistas gravadas em programas de rádio ou televisão, ou ainda, em jornais e revistas da época. Porém, reconhecer a dificuldade de obtenção dessas fontes não deveria se apresentar como um obstáculo intransponível ao desenvolvimento das pesquisas, pois "devemos fazer o inventário dos arquivos do silêncio, e fazer a história a partir dos documentos e das ausências de documentos" (LE GOFF, 1996, p. 109).

Uma interessante alternativa aos professores que utilizam canções enquanto fonte para o ensino de história consiste em mapear o cenário cultural artístico-musical, em busca de músicos instrumentistas, intérpretes e compositores locais. Devemos superar a comodidade que os discos de vinil, CD's ou fitas cassete podem nos oferecer. Enquanto procedimento metodológico complementar, fundamental e pertinente, a inserção de canções produzidas por compositores locais contribui sobremaneira com a investigação sobre a história local, que tem sido indicada como necessária para o ensino, possibilitando a compreensão do entorno do aluno, identificando o passado sempre presente nos vários espaços de convivência - escola, casa, comunidade, trabalho e lazer - igualmente por situar os problemas significativos da história do presente. Neste sentido, a memória é, sem dúvida, aspecto relevante na configuração de uma história local tanto para historiadores como para o ensino. A final, "O papel do ensino de História na configuração identitária dos alunos é um dos aspectos relevantes para considerar ao proporem-se estudos da história local.” (BITTENCOURT, 2005, p. 168-169).

De posse dessas fontes, enquanto aproximações entre ensino e pesquisa sua utilização deve ser orientada teoricamente, tanto por pesquisadores quanto professores, priorizando a apreensão das especificidades destes documentos através da observância do contexto histórico, 
procurando situar os vínculos e relações do documento e seu (s) produtor (es) com seu tempo e espaço em relação ao processo social de criação e produção da canção popular, afinal, o processo criativo "já supõe certas preocupações com códigos e com o universo da criação da cultura popular" (MORAES, 2000, p. 216).

[...] é fundamental a articulação entre "texto" e "contexto" para que a análise não seja reduzida, reduzindo a própria importância do objeto analisado. $\mathrm{O}$ grande desafio de todo o pesquisador em música popular é mapear as camadas de sentido embutidas numa obra musical, bem como suas formas de inserção na sociedade e na história, evitando ao mesmo tempo, as simplificações e mecanismos analíticos que podem deturpar a natureza polissêmica e complexa de qualquer documento de natureza estética [...] (NAPOLITANO, 2005, p. 77-78).

As articulações entre "texto" (letra) e "contexto" oferecem ao pesquisador e professor a possibilidade de ampliar os horizontes narrativos e interpretativos dessas fontes, uma vez que a canção popular, enquanto expressão artística nas suas diversas variantes, certamente é a que mais embala e acompanha as diferentes experiências humanas. Além disso, a canção pode alcançar ampla dimensão da realidade social (MORAES, 2000, p. 204), refletindo individualidades e coletividades de fundamental relevância para o processo de aprendizagem histórica.

Através da contextualização das canções populares desses artistas desconhecidos por parte dos pesquisadores e professores se torna possível estabelecer diálogos com diferentes concepções sociais e temporalidades nas quais "não só encontramos o Povo como objeto de um discurso - discurso sobre o Povo e para o Povo, - e como sujeito desse discurso - do Povo como encontramos o movimento invisível que conduz os primeiros ao resultado final, isto é, uma fala que diz ao Povo" (CHAUI, 1987, p. 115), uma vez que, as canções são produções sociais de sentido e seus conteúdos textuais construções de discursos (NEDER, 2012, p. 80).

A música popular, sobretudo na sua manifestação específica que é a canção registrada em fonograma, não se define unicamente pelos seus atributos estruturais melódico-harmônicos pensados como propriedades internas definidoras de formas e gêneros. A rigor, a forma privilegiada da música popular é a canção, tal como consagrada pela indústria do disco [...] (NAPOLITANO, 2007, p. 155).

Seguindo os rastros da historiografia da música brasileira, é possível considerar que o caráter popular da canção identificada com a sigla MPB (Música Popular Brasileira) ao longo das décadas de 1960, 70 e 80 foi, em parte, construído através de diretrizes da indústria fonográfica que reelaborou e utilizou diversos elementos das identidades culturais existentes no país - evidente em muitas canções do gênero - objetivando explorá-los comercialmente através de produtos musicais destinados ao consumo em larga escala. Certamente, analisar tal 
produção, seus agentes (empresários, produtores musicais, compositores, intérpretes, instrumentistas, entre outros) e os movimentos musicais inseridos no contexto da indústria cultural é de suma importância para o desenvolvimento da historiografia da música brasileira, porém, não deve se constituir como único campo de investigação ou terreno hegemônico de compreensão da canção popular e das culturas que circundam e dialogam com essa produção.

[...] precisamos ter cuidado quanto a generalizações como "cultura popular". Esta pode surgir, numa inflexão antropológica influente no âmbito dos historiadores sociais, uma perspectiva ultraconsensual dessa cultura, entendida como "sistema de atitudes, valores e significados compartilhados, e as formas simbólicas (desempenhos e artefatos) em que se acham incorporados. Mas uma cultura é também um conjunto diferente de recursos, em que há sempre uma troca entre o escrito e o oral, o dominante e o subordinado, a aldeia e a metrópole; é uma arena de elementos conflitivos, que somente sob uma pressão imperiosa - por exemplo, o nacionalismo, a consciência de classe ou a ortodoxia religiosa predominante - assume a forma de um "sistema". E na verdade o próprio termo "cultura", com sua invocação confortável de um consenso, pode distrair nossa atenção das contradições sociais e culturais, das fraturas e oposições existentes dentro do conjunto. (THOMPSON, 1998, p. 17)

Sendo assim, as manifestações ligadas à construção da música/canção popular, ao longo das décadas de 1960, 70 e 80, não estiveram necessariamente subordinadas à indústria do disco, muito menos dependente dos grandes eventos musicais realizados pelas emissoras de televisão (Festivais de Música da Televisão) que expunham a produção musical dos artistas para todas as partes do país. Em outros termos, não há uma forma privilegiada da canção, assim como, não deveriam haver formas privilegiadas de culturas para o ensino de história.

Grande parte das manifestações acerca das culturas populares brasileiras e seus diálogos com influencias musicais estrangeiras reproduzidas nos LP's comercializados pelas lojas especializadas foram construções ou escolhas advindas do interesse de grupos ligados ao mercado musical. O conteúdo de muitas canções gravadas nos discos da época respeitava a lógica comercial dos empresários que priorizavam a forja de registro de canções com elementos culturais comuns, compartilhados pela sociedade brasileira como um todo,

[...] a indústria fonográfica sempre teve um papel-chave nas convenções particulares ao gênero e, através de estratégias específicas, procuram guiar a criação, a circulação e o consumo da música, como formas de manter seus lucros. A indústria procura por em ordem o mercado musical com o uso dos selos de gênero. É ela que vai ser a responsável por privilegiar e divulgar os gêneros musicais transformando rock, reggae, blues, salsa, rap, jazz em gêneros universais, a partir de um conjunto de práticas profissionais, divisões ideológicas e conflitos. (VLADI, 2010, p. 9)

Quanto mais amplo o alcance da canção, ao menos em tese, maior o consumo e, desta forma, aumentava-se a chance de obtenção de lucro neste evidente processo de homogeneização 
e massificação da canção dotada de elementos das culturas populares manifestadas no país. Acerca da cultura de massa e da cultura popular, Ecléia Bosi afirma que,

[...] uma realidade cultural imposta "de cima para baixo" (dos produtores para os consumidores) e uma realidade cultural estruturada a partir de relações internas no coração da sociedade. A este segundo sistema de ideias, imagens, atitudes, valores é que tradicionalmente se da o nome de cultura popular [...] (BOSI, 1977, p. 53).

Torna-se mais coerente apresentar a produção musical ligada ao mercado fonográfico enquanto canção popular de massa, até porque, havia muito cuidado e preocupação com as escolhas das canções que poderiam 'emplacar' um sucesso de vendas. A imposição das gravadoras e demais profissionais que trabalhavam pensando as canções enquanto produto que em breve poderiam ser colocados à venda, começava a partir da entrega do sempre abundante material sonoro e textual aos encarregados pelas escolhas, o que acabava por aumentar ainda mais a possibilidade de êxito do processo e o retorno financeiro do investimento acrescido da maior lucratividade possível, neste sentido:

[...] entre a quantidade de canções que são apresentadas cada ano junto às empresas gravadoras, cantores, músicos e sociedades de direitos autorais e as que chegam ao público, existe um processo de seleção que se opera formal ou informalmente, de acordo com as necessidades e possibilidades do mercado e os interesses dos participantes do processo [...] (MEDINA, 1973, p. 76).

Ainda que alguns artistas consagrados pelo sucesso de público, advindo de seus expressivos números em relação à vendagem de discos, tivessem relativa ou, em alguns casos, total autonomia na escolha das canções que comporiam seus trabalhos fonográficos comercializados no circuito da canção popular "socialmente engajada" (NAPOLITANO, 2001, p. 226), compositores que não faziam parte desta teia comercial da canção popular ligada à sigla MPB, até alguns anos atrás, ainda não integravam a história da música brasileira, sobretudo, em razão do ínfimo interesse dos historiadores da música brasileira. Raras eram as exceções, tanto em sala de aula quanto em relação ao desenvolvimento de pesquisas acadêmicas.

$\mathrm{Na}$ esteira das preferências de pesquisa e ensino no Brasil, o historiador e professor do Ensino Fundamental, Paulo Cesar de Araújo rompeu o status quo da historiografia da música popular brasileira ao publicar, em 2002, a obra Eu não sou cachorro, não: música popular cafona e ditadura militar. Indagando acerca dos motivos pelos quais as letras de canções utilizadas em livros didáticos ignoravam expressivas parcelas de compositores com os quais a maioria da população brasileira se identificava - Nelson Ned, Odair José, Benito de Paula, Wando, Agnaldo Timóteo, entre outros - o pesquisador apontou como jornalistas, críticos musicais, pesquisadores, produtores e alguns artistas intelectualizados subjugaram e 
menosprezaram artistas de classes sociais menos favorecidas, procurando silenciar a música considerada 'cafona' por meio da exclusão e do preconceito, expondo o caso da coleção História da música popular brasileira, vendida em bancas de jornal e do acervo de entrevistas do Museu da Imagem e do Som (MIS) do Rio de Janeiro, no qual os dirigentes ou curadores se omitiram sobre este segmento artístico da nossa música popular.

A primazia que anteriormente comprometia a compreensão ampla dos aspectos socioculturais e políticos que compõem as manifestações populares no Brasil, expostas através das concepções sociais dos compositores da nossa música, foi duramente criticada através da problematização proposta por Paulo Cesar de Araújo. Além disso, a obra pode ser considerada como um divisor de águas que inaugura uma nova etapa na historiografia da música popular brasileira, influenciando na escrita acadêmica e refletindo no conteúdo relacionado à utilização de canções para o ensino de história.

Quando tomamos como ponto de partida a análise das obras de compositores conhecidos do grande público, independente do segmento da música popular do qual fazem parte, integrando ao processo de ensino de história, canções de compositores desvinculados dos meios de comunicação de massa e da indústria fonográfica, as possibilidades de ampliação do campo de análise acabam acrescidas de modo significativo, possibilitando uma maior compreensão dos processos históricos, onde artistas do povo também atuaram como agentes históricos, agindo enquanto compositores, intérpretes e instrumentistas, portanto:

[...] a pluralidade cultural permite assinalar a singularidade histórica e social de uma cultura; permite também que não ocultemos a dificuldade contida no termo "povo", pois lato sensu costuma-se considerar como povo não só o operariado, o campesinato e os assalariados dos serviços, como ainda camadas que constituem a pequena burguesia, não sendo possível, portanto, agrupar em um todo homogêneo as manifestações culturais desses vários setores da sociedade; permite, enfim, que não caiamos no embuste dos dominantes, para os quais interessa justamente que a multiplicidade cultural seja encarada como multiplicidade empírica de experiências unificáveis e homogêneas, ou, para usar o jargão em voga, como multiplicidade destinada a "integração nacional". Se mantivermos presente e viva a pluralidade, poderemos talvez marcar a diferença entre a manifestação operária, a camponesa e a pequeno-burguesa; poderemos também permanecer abertos para uma criação que é sempre múltipla [...] (CHAUI, 1988, p. 122-123).

Para buscar a compreensão abrangente dos aspectos que compõem as pluralizadas culturas populares brasileiras, deve-se incluir um esforço de análise de obras dos demais agentes históricos que compuseram o processo social de construção da história da música e da canção popular brasileira, ambas, forjadas diariamente pela imensa maioria dos artistas desconhecidos do grande público, espalhados por diversas partes do país (TINHORÃO, 1976). Tal passo 
representa ainda a possibilidade de contato com o passado de setores da população brasileira, onde as práticas culturais inerentes à produção de canções precederam a existência da indústria fonográfica. Desta feita, novos elementos podem ser acrescentados ao processo de aprendizagem. A experimentação do tempo através da canção passa a ser ainda mais significativa, pois desenvolve novas aptidões de significação ao tempo, devido à ampliação significativa dos horizontes da abordagem.

\section{Outras vozes da canção popular}

Em relação às canções populares enquanto produção sociocultural de sentido no tempo, protagonizando ou auxiliando na instrumentalização de processos cognitivos em história, observadas suas peculiaridades objetivas e subjetivas, bem como, suas temporalidades, através das "camadas de memória" (THOMPSON, 1992, p. 197) existentes em seu conteúdo musical cantado e (ou) escrito, inerentes ao seu processo social e individual de produção/composição,

“... o passado se torna presente de modo que o presente é entendido e perspectivas sobre o futuro podem ser formadas. A perspectiva sobre o passado domina, é claro, uma vez que a consciência histórica funciona através da memória... a memória encontra-se intimamente ligada as perspectivas futuras. O próprio presente é visto, interpretado e representado como um processo em curso na estreita relação da memória com a expectativa de futuro." (RÜSEN, 2010, p. 79)

A atribuição de significado ao tempo através da rememoração do conteúdo de canções enquanto processo cognitivo e consciente acerca do passado histórico pressupõe o devir enquanto espaço inacabado de compreensão do presente. Portanto, refletir acerca do ensino de história através da música, especificamente em relação à utilização da canção popular enquanto representativa das manifestações socioculturais e políticas relacionados a determinados períodos históricos, além de auxiliar na condução de processos cognitivos de aprendizagem, pode ainda favorecer na elaboração de projetos futuros, os quais sejam orientados por questões referentes às identidades históricas.

Pode-se, em suma, definir esse ato de rememoração como o ato de dar sentido à experiência do tempo. A consciência histórica funciona por meio da memória; ela aproxima as três dimensões do tempo; cumpre a função prática de orientar um sujeito em direção ao tempo. (RÜSEN, 2010, p. 80)

Jörn Rüsen sublinha que a "consciência histórica vem à tona ao contar narrativas, isto é, histórias, que são uma forma coerente de comunicação, pois se referem à identidade histórica de ambos: comunicador e receptor." (RÜSEN, 2010, p. 80), uma vez que, a memória da consciência histórica é determinada pelas exigências dos sujeitos envolvidos no processo de 
aprendizagem, neste caso, pesquisadores, professores e alunos. Ainda assim, trabalhar com identidades históricas e relacioná-las, por exemplo, ao contexto da Ditadura Civil-Militar, repercutindo as concepções sociais de compositores populares desvinculados da indústria fonográfica, consiste adentrar em territórios de disputas de memória, sobretudo permeado por polarizações políticas, nos quais o processo de reelaboração do passado "a memória individual existe sempre a partir de uma memória coletiva, que também é seletiva... a memória é sempre fruto de uma interação entre diferentes agentes, internos e externos" (VASCONCELOS, 2009, p. 66), em outras palavras, "nossas lembranças permanecem coletivas e nos são lembradas por outros, ainda que se trate de eventos em que somente nós estivemos envolvidos e objetos que somente nós vimos. Isto acontece porque jamais estamos sós.” (HALBWACHS, 2006, p. 30)

Ao rememorar o passado através da utilização do conteúdo de canções populares construídas neste período conturbado da história brasileira, os professores devem privilegiar a exposição de fontes com visões antagônicas, oportunizando aos alunos a ampliação das narrativas históricas que possam num primeiro momento, orientar sua identidade histórica, uma vez que:

Como ser social, os alunos não são iguais. Constroem-se nas vivências e nas experiências sociais em diferentes lugares, em casa, na igreja, nos bairros, escolas, e são construídos como sujeitos diferentes e diferenciados, no seu tempo-espaço. E nós, professores, não estamos diante de alunos iguais, mas jovens ou crianças que são singulares e heterogêneos socioculturalmente, e imersos na complexidade da vida humana. (SOUZA, 2004, p. 10)

É necessário que a contumaz homogeneização relacionada à seleção de memórias individuais e coletivas retratadas nas canções populares com conteúdo censurado e de compositores engajados ao longo da última ditadura brasileira seja atualizada enquanto recurso didático para o ensino de história, dado à heterogeneidade sociocultural e polarização política da época, que em certa medida ainda é experimentada em diversificados ambientes que não estejam propriamente subordinados as atividades escolares dos alunos.

[...] ensinar história na escola significa permitir aos estudantes abordar as historicidades de suas determinações socioculturais, fundamento de uma compreensão de si mesmos como agentes históricos e das suas identidades como construção do tempo histórico. O presente, que é espaço/tempo dos estudantes, de onde eles olham para si mesmos e para o passado, torna-se histórico, na medida em que, passo a passo, o professor de História consegue historicizar as instituições, as políticas, os modelos culturais, os modos de ser e, sobretudo, as identidades. Trata-se de levar as novas gerações a conhecerem suas próprias determinações, a construir relações de pertencimento a um grupo, a uma história coletiva e a lutas coletivas. (PEREIRA \& SAFFER, 2008, p. 119) 
Diante da variedade obtida com a inserção e utilização de outras vozes da canção popular com conteúdos dissonantes, provenientes de artistas que ocupam a 'periferia da música popular brasileira' é possível vislumbrar o processo de ensino enquanto instrumento capaz de trazer à tona uma consciência histórica heterogênea, em razão da pluralidade cultural de seus compositores, afinal, é evidente as tensões entre as experiências temporais, as identidades históricas e as expectativas de futuro de todos os envolvidos no alcance da ação narrativa do passado exposta pelo professor em sala de aula, articulada a utilização didática da canção. Luis Fernando Cerri chama nossa atenção para o caráter das identidades no processo de formação da consciência histórica.

A formação da consciência histórica é fenômeno social com múltiplos elementos e variáveis. Ao considerar o conceito, dimensiona-se o efetivo papel da disciplina de história na escola, ou seja, o de um dos fatores intervenientes nesse fenômeno. Assim, a Didática da História passa a exigir um redimensionamento, também, dos objetivos disciplinares, deixando para trás as listas de conteúdos como centro do debate. Esse centro passa a ser a preocupação com a identidade de quem receberá a ação do professor de história. Num contexto de crise de todos os grandes sistemas explicativos do tempo e que têm a pretensão de definir os destinos das pessoas, os objetivos do ensino deslocam-se para promoção de identidades que possam ser refletidas e assumidas seletiva e criticamente pelo sujeito, em vez de impostas desde fora. Em outros termos, os objetivos do ensino deslocam-se para a promoção de identidades com maior autonomia, bem como para a prevenção de identidades não-razoáveis. (CERRI, 2010, p. 270-271)

Utilizar canções populares dissonantes para o ensino de história, além de promover identidades com maior autonomia, pode ainda auxiliar sobremaneira na prevenção de identidades não-razoáveis. Neste sentido, pontualmente através de canções produzidas nas décadas de 1960 e 1970, desvinculadas dos meios de comunicação de massa e da indústria fonográfica, utilizadas nas aulas de história sobre a temática referente à Ditadura Civil-Militar, uma interessante perspectiva teórico-metodológica reside na exposição das concepções sociais de seus compositores observadas às manifestações de conformismo e resistência enquanto aspectos das culturas populares que compõem o Brasil (CHAUI, 1987). Vejamos dois exemplos de canções com tais perspectivas, ambas integram o contexto de festivais de música que ocorreram ao longo da década de 1970 na cidade de Rio Grande - RS.

O jovem Farydo Salomão Junior, filho do ex-prefeito da cidade cassado logo após o Golpe de 1964, construiu a canção vencedora de um festival de música, denominada "Apelos”, com o objetivo de manifestar implicitamente seu descontentamento e inconformismo em relação às práticas antidemocráticas levadas a cabo após o Golpe de 1964.

Manhã branca / Maré mansa / Brisa calma à beira-mar / Jangadeiro se despede / Da Maria e vai pescar / O Jangadeiro pega a rede / A jangada e vai pro mar 
/ Tem no peito uma esperança / A tardinha retornar / Aconteceu que o bom tempo / Foi ingrato em alto-mar / Transformou-se em vento forte / Querendo a jangada virar / E ao bom homem do mar / Janaina foi buscar / E o levou pra outras terras / As boas terras de Aiocá / Jangou, Jangou / Jangadeiro foi pro mar / Lançar sua rede / Nas águas de Iemanjá / E agora seus apelos são: / Ah! Se eu pudesse voltar.

A licença poética inerente à temática de sua canção acerca da atividade pesqueira atividade muito presente no cotidiano da cidade - lhe autorizou a driblar a censura da época fazendo uso do trocadilho "Jangou, Jangou", em letras maiúsculas, para se referir a figura do ex-presidente João Goulart. O nome da esposa do "Jangadeiro", "Maria", aparece enquanto uma menção à esposa de Goulart, Maria Teresa Goulart e "Janaína" também cultuada nas religiões de matriz africana como Iemanjá, é citada como a responsável por buscar e conduzir o "Jangadeiro" até as terras "Aiocá", uma alusão à ida de Jango para o exílio no Uruguai. Nas últimas linhas da canção, o compositor concluiu a ideia através do restabelecimento da democracia no país, destacando que o "Jangadeiro" faz "apelos" para retornar ao seu lugar, ou seja, retomar o cargo de presidente do Brasil.

No mesmo evento a canção premiada com o $4^{\circ}$ lugar, denominada "E o gigante despertou" de autoria de Lindomar Duarte, expunha através do conformismo uma mensagem de otimismo em relação aos rumos do Brasil, destacando também as belezas e potencialidades do país e do seu povo de modo ufanista, e, exaltando a política praticada pelo Governo Militar, inclusive citando o slogan "Ninguém segura mais esse país".

Brasil, o meu Brasil / E o gigante despertou / Brasil dos campos imensos, das praias sem fim / De um povo que canta, que samba / És terra do amor / Estradas vão se desbravando / É o petróleo jorrando, é um povo a vibrar / Com a magia do teu futebol / Salve meu Brasil, sigamos a corrente / Avante meu país continente / Do futuro sorridente de todas as gerações / Vai mostrar ao mundo inteiro / Do que é capaz o brasileiro / Mobral, é a Transamazônica, é o homem do campo plantando feliz / Ninguém segura mais este país.

Diante do conformismo e resistência expostos através das concepções sociais destes dois compositores com visões antagônicas em relação a um mesmo contexto sociocultural e político qual canção tomar como representativa da época?

Essa é uma reflexão extremamente necessária quando pesquisadores e professores utilizam canções populares como fonte de ensino e pesquisa, pois cabe a eles fazerem uso da pluralidade de elementos culturais e da polarização política tão característica da sociedade brasileira, refletida através das canções como contribuições efetivas para debates construtivos acerca do entendimento do passado, presente e das perspectivas de futuro. Até porque, os 
mesmos indivíduos que se identificam com a religiosidade retratada, por exemplo, na canção “Apelos” podem não concordar com o teor político nela inserido.

Nesse processo de exposição das canções com elementos comuns compartilhados e contraditórios deve-se agir, no intuito de estabelecer significado ao tempo, sobretudo, através de narrativas que extrapolem a polarização política enquanto manifestação sociocultural característica dos processos históricos brasileiros, visando à promoção de identidades autônomas, prevenindo identidades não-razoáveis e mantendo problematizações que fomentem debates orientados pela pluralidade cultural promotora de transigências, onde projetos futuros com orientações democráticas possam se tornar viáveis através das experiências vivenciadas no tempo presente pelo ensino de história.

\section{Considerações finais}

A proposta deste ensaio foi refletir acerca das relações entre história e a canção popular brasileira enquanto suporte didático, elencando possibilidades teóricas e metodológicas através de inflexões que contribuam para a ascensão de "outras vozes" da música popular brasileira, expõe a necessidade de darmos um passo adiante na construção de trajetórias de pesquisas que possam subsidiar novas perspectivas de ensino e aprendizagens históricas.

Essa intrincada relação exige dos historiadores atitudes de pesquisas positivas no que diz respeito à conscientização e experimentação acerca das temporalidades, bem como, a elaboração de problematizações que desenvolvam novas competências de atribuição de significado ao tempo, sobretudo, no sentido de desvelar novos contextos e agentes históricos intrínsecos às manifestações socioculturais inerentes a produção musical desvinculada dos meios de comunicação de massa e da indústria fonográfica.

Dinamizar as pesquisas acerca da música popular brasileira através da desmitificação dos artistas consagrados, levando em consideração a pluralidade cultural do povo brasileiro enquanto participe do processo de construção da história da música e da canção popular em nosso país, para então esboçar a gênese de caminhos ainda mais participativos e inclusivos, pode garantir a ampliação de diálogos permeados e intermediados por identidades culturais que são orientadoras de experiências temporais fundamentais para o ensino e a aprendizagem em história.

\section{Referências Bibliográficas}


ARAÚJO, Paulo César. Eu não sou cachorro, não. São Paulo: Record, 2005.

BOSI, Ecléa. Cultura de massa e cultura popular: leituras de operárias. Petrópolis: Vozes, 1977.

CANDAU, Joel. Memória e Identidade. São Paulo: Contexto, 2014.

CERRI, Luis Fernando. Didática da História: uma leitura teórica sobre a História na prática. Revista de História Regional,15(2): 264-278, Inverno, 2010.

CHAUI, Marilena. Cultura do povo e autoritarismo das elites. In: VALLE, Edênio \& QUEIRÓZ, José J. A cultura do povo. $4^{\mathrm{a}}$ Ed., São Paulo: Cortez: Instituto de Estudos Especiais, 1988.

QUEIRÓZ, José J. Cultura e democracia: o discurso competente e outras falas. São Paulo: Ed. Moderna, 1980.

QUEIRÓZ, José J. Conformismo e Resistência: Aspectos da cultura popular no Brasil. Editora Brasiliense: São Paulo, $6^{\circ}$ Edição, 1987.

DAVID, Célia Maria. Música e ensino de História: uma proposta. Revista Digital Conteúdos e Didática de História - Universidade Estadual Paulista, 2012.

HALBWACHS, Maurice. A memória coletiva. São Paulo: Centauro, 2006.

LE GOFF, Jacques. História e memória. Campinas: Ed. Unicamp, 1996.

MEDINA, Carlos Alberto de. Canção popular e comunicação: um ensaio sociológico. Petrópolis: Vozes, 1973.

MELLO, Zuza Homem de. A Era dos Festivais: uma parábola. São Paulo: Ed. 34, 2003.

MORAES, José Geraldo Vinci de. História e música: canção popular e conhecimento histórico.

Revista Brasileira de História. São Paulo, v. 20, n 39, 2000.

NAPOLITANO, Marcos. A arte engajada e seus públicos (1955/1968). Estudos Históricos, Rio de Janeiro, $\mathrm{n}^{\mathbf{0}}$ 28, 2001.

NAPOLITANO, Marcos. Seguindo a canção: Engajamento político e indústria cultural na MPB (1959-1969). São Paulo: Editora Annablume, FAPESP, 2001.

NAPOLITANO, Marcos. A música popular brasileira dos anos 70: resistência política e consumo cultural. IV Congresso de la Rama latinoamericana del IASPM (Cidade do México, abril de 2002).

NAPOLITANO, Marcos. A MPB sob suspeita: a censura musical vista pela ótica dos serviços de vigilância política (1968-1981). Revista Brasileira de História. São Paulo, V. 24, n 47, 2004.

NAPOLITANO, Marcos. História e música. Belo Horizonte: Autêntica, 2005.

NAPOLITANO, Marcos. História e música popular: um mapa de leituras e questões. Revista do Departamento de História, USP, ${ }^{\circ}$ 157, 2007.

NEDER, Álvaro. MPB: identidade, intertextualidade e contradição no discurso musical. Revista Brasileira de Estudos da Canção, Natal, v.1, n.1, jan-jun 2012.

OLIVEIRA, Terezinha \& VIDIGAL, Andressa Gonçalves. Música e educação na Idade Média. Um estudo de Hildegard Von Bingen. X Jornada de Estudos Antigos e Medievais. II Jornada Internacional de Estudos antigos e Medievais. Universidade Estadual de Maringá, 2011.

PEREIRA, Nilton Mullet \& SEFFNER, Fernando. O que pode o ensino de história? Sobre o uso de fontes na sala de aula. Anos 90, Porto Alegre, v. 15, n. 28, dez. 2008.

SCHMIDT, Maria Auxiliadora; Barca, Isabel; Martins, Estevaão de Rezende (Org.) Jörn Rüsen e o ensino de história. Curitiba: Ed. UFPR, 2010.

SILVA, Alberto Moby Ribeiro da. A breve e profícua vida do compositor popular Julinho da Adelaide. In: História: Questões \& Debates, Editora da UFPR, Curitiba, n. 31, 1999.

SOARES, Olavo Pereira. A música nas aulas de história: o debate teórico sobre as metodologias de ensino. Revista História Hoje, v. 6, nº 11, 2017. 
SOUZA, Jusamara. Educação musical e práticas sociais. Revista da ABEM, Porto Alegre, V. 10, 7-11, mar. 2004.

THOMPSON, Paul. A voz do passado: história oral. Rio de Janeiro: Paz e Terra, 1992.

THOMPSON, E. P. Costumes em comum. São Paulo: Companhia das Letras, 1998.

TINHORÃO, José Ramos. Música popular: os sons que vem da rua. São Paulo: Edições Tinhorão, 1976.

TINHORÃO, José Ramos. Música Popular: do Gramofone ao Rádio e TV. São Paulo: Ática, 1981.

VASCONCELOS, Cláudio Beserra. As análises da memória militar sobre a ditadura: balanço e possibilidades. Estudos Históricos, Rio de Janeiro, vol. 22, no 43, janeiro-junho de 2009.

VLADI, Nadja. O negócio da música - como os gêneros musicais articulam estratégias de comunicação para o consumo cultural. XXXIII Congresso Brasileiro de Ciências da Comunicação, Caxias do Sul/RS, 2010. 